\title{
EFISIENSI TEKNIS USAHATANI JAGUNG DI DESA GUNUNGTANJUNG KECAMATAN GUNUNGTANJUNG KABUPATEN TASIKMALAYA
}

\section{TECHNICAL EFFICIENCY OF MAIZE FARMING IN GUNUNGTANJUNG VILLAGE, GUNUNGTANJUNG DISTRICT, TASIKMALAYA REGENCY}

\author{
AGUS HIDAYAH MULYANA*¹, TRISNA INSAN NOOR ${ }^{2}$, \\ AGUS YUNIAWAN ISYANTO ${ }^{1}$ \\ ${ }^{1}$ Fakultas Pertanian, Universitas Galuh \\ ${ }^{2}$ Fakultas Pertanian, Universitas Padjadjaran \\ *E-mail: ahidayah16@gmail.com
}

\begin{abstract}
ABSTRAK
Peningkatan produksi jagung dilakukan untuk memenuhi kebutuhan nasional terutama sebagai bahan pakan ternak yang jumlahnya semakin naik seiring dengan meningkatnya produksi ternak unggas. Kabupaten Tasikmalaya merupakan salah satu daerah produksi jagung dimana Kecamatan Gunungtanjung memiliki produktivitas terendah dalam usahatani jagung. Penelitian ini bertujuan untuk mengetahui; (1) Faktor-faktor yang berpengaruh terhadap produksi pada usahatani jagung, (2) Tingkat efisiensi teknis usahatani jagung, dan (3) Faktor-faktor yang berpengaruh terhadap inefisiensi teknis pada usahatani jagung. Metode yang digunakan yaitu studi kasus dengan penarikan responden dilakukan secara sensus. Pemilihan tempat penelitian dilakukan secara purposif dengan pertimbangan bahwa Desa Gunungtanjung memiliki luas tanam jagung terbesar di Kecamatan Gunungtanjung Kabupaten Tasikmalaya. Pendekatan empiris dilakukan dengan menggunakan fungsi produksi Frontier Stokhastik. Hasil penelitian menunjukkan: (1) Faktor yang berpengaruh terhadap produksi pada ushatani jagung yaitu luas lahan, pupuk urea, dan tenaga kerja, (2) Tingkat efisiensi berada pada kategori efisien dengan nilai rata-rata 0.83 , dan (3) Faktor yang berpengaruh terhadap inefisiensi teknis pada usahatani jagung yaitu penguasaan luas lahan dan intensitas penyuluhan.
\end{abstract}

Kata kunci: efisiensi teknis, usahatani jagung, produksi

\begin{abstract}
Increased production of maize is done to meet the needs of the national especially as livestock feed material that the number is rising in line with the increasing of poultry production. Tasikmalaya Regency as one of the areas of maize production, where Gunungtanjung district became the lowest productivity area. The research aims to know: (1) Factors that influence the production of maize farming, (2) The level of technical efficiency of maize farming, and (3) Factors that affect the technical inefficiency of maize farming. The method used is the case study with the withdrawal of respondents by census. The selection of the research place is purposive with the consideration that Gunungtanjung village has the largest maize planting area in the district of Gunungtanjung Tasikmalaya District. The empirical approach was carried out using the Stokhastic Frontier production function. The results showed that: (1) Factors that have an effect on the production of the maize farming, namely land area, urea fertilizer, and labor, (2) The level of efficiency is in the category of efficient with an average value of 0.83, and (3)Factors that affect the technical inefficiency in maize farming is the mastery of land area and extension intensity
\end{abstract}

Keywords: technical efficiency, maize farming, production 


\section{PENDAHULUAN}

Upaya pemerintah dalam pemenuhan kebutuhan pangan masyarakat dilakukan dengan intervensi melalui kebijakan yang tertuang dalam RENSTRA pembangunan pangan dan pertanian 2019-2024 dengan tujuan, yaitu: (a) meningkatkan ketersediaan dan ekspor pangan; (b) meningkatkan lapangan kerja; (c) mengurangi kemiskinan; dan (d) meningkatkan ksejahteraan petani.

Kelompok pangan padi-padian yang biasa dijadikan sebagai pangan alternatif pengganti beras yaitu jagung. Jagung termasuk tanaman serealia yang mengandung banyak serat pangan yang popular diteliti potensi kandungan unsur pangan fungsionalnya (Suarni, 2009).

Tabel 1. Perkembangan Konsumsi Jagung Basah dalam Rumah Tangga di Indonesia 2013-2018

\begin{tabular}{|c|c|c|c|}
\hline \multirow[b]{2}{*}{ Tahun } & \multicolumn{2}{|c|}{ Konsumsi } & \multirow[b]{2}{*}{$\begin{array}{c}\begin{array}{c}\text { Per- } \\
\text { tumbuhan } \\
(\%)\end{array}\end{array}$} \\
\hline & $\begin{array}{c}(\mathrm{kg} / \\
\text { kapita/ } \\
\text { minggu) }\end{array}$ & $\begin{array}{c}\text { (kg/ } \\
\text { kapita/ } \\
\text { tahun) }\end{array}$ & \\
\hline 2013 & 0,011 & 0,574 & 0,00 \\
\hline 2014 & 0,013 & 0,666 & 16,03 \\
\hline 2015 & 0,029 & 1,512 & 127,22 \\
\hline 2016 & 0,035 & 1,825 & 20,69 \\
\hline 2017 & 0,026 & 1,335 & $-26,82$ \\
\hline 2018 & 0,029 & 1,534 & 14,87 \\
\hline $\begin{array}{r}\text { Rata- } \\
\text { rata }\end{array}$ & 0,024 & 1,241 & 25,33 \\
\hline
\end{tabular}

Sumber: Pusdatin, Kementan. 2019.

Selain sebagai bahan pangan, jagung juga dijadikan sebagai bahan baku pembuatan pakan ternak unggas. Proporsi penggunaan jagung dalam pembuatan pakan ayam ras mencapai 51,4 persen dari total bahan baku yang digunakan (Tangendjaja dkk, 2002).

Wilayah yang menjadi daerah pengembangan komoditas jagung di Provinsi Jawa Barat salah satunya yaitu Kabupaten Tasikmalaya. Luas panen jagung di Kabupaten Tasikmalaya pada tahun 2017 tercatat seluas 13.719 ha dengan total produksi sebesar 89.390 ton jagung pipilan kering. Kecamatan Gunungtanjung menjadi daerah dengan produktivitas terendah di Kabupaten Tasikmalaya dengan rata-rata produktivitas jagung sebesar 57,47 ku/ha (BPS Kab. Tasikmalaya, 2018). Rendahnya produktivitas yang dihasilkan bisa disebabkan oleh pengelolaan dari penggunaan input produksi dalam berusahatani jagung belum digunakan secara maksimal atau efisien.

Perbandingan output dan ukuran input produksi dalam usahatani dapat menggambarkan tingkat efisiensi usahatani yang dilaksanakan. Konsep efisiensi dipublikasikan Michael Farrell dengan menginterpretasikan sebagai kemampuan organisasi input produksi dalam menghasilkan produksi output tertentu dengan tingkat biaya yang minimum (Kopp dalam Kusumawardani, 2001).

Faktor yang mempengaruhi efisiensi teknis usahatani jagung menurut Utama 
(2004), penggunaan benih dan tenaga kerja berpengaruh nyata terhadap peningkatan produksi jagung. Penelitian Mandei (2015), menyatakan bahwa penggunaan tenaga kerja, benih, dan herbisida berpengaruh terhadap produksi jagung. Sedangkan untuk jumlah tanggungan keluarga dan lama pendidikan mempengaruhi inefisiensi teknisnya. Penelitian Sumarno, dkk (2015) menyatakan pendidikan petani, frekuensi penyuluhan, keikutsertaan dalam kelompok tani dan akses kredit berpengaruh terhadap inefisiensi usahatani jagung. Penelitian Manurung, dkk (2018), menyatakan bahwa penggunaan benih, pupuk kimia, dan tenaga kerja berpengaruh terhadap produksi tanaman jagung. Sementara luas lahan dan tingkat pendidikan berpengaruh terhadap inefisiensi teknisnya.

Penelitan ini bertujuan untuk (1) mengidentifikasi faktor-faktor yang berpengaruh terhadap produksi pada usahatani jagung, (2) mengetahui tingkat efisiensi teknis usahatani, dan (3) menganalisis faktor-faktor yang mempengaruhi inefisiensi teknis pada usahatani jagung di Desa Gunungtanjung Kecamatan Gunungtanjung Kabupaten Tasikmalaya.

\section{METODE PENELITIAN}

\section{Jenis Penelitian}

Penelitian ini merupakan penelitian kuantitatif. Menurut Darmawan (2014), penelitian kuantitatif adalah suatu proses menemukan pengetahuan yang menggunakan data berupa angka sebagai alat menemukan keterangan mengenai apa yang ingin kita ketahui.

Penelitian ini dilakukan di Desa Gunungtanjung Kecamatan Gunungtanjung Kabupaten Tasikmalaya. Penelitian ini dilakasanakan dengan menggunakan metode studi kasus dengan mengambil kasus pada petani jagung di Desa Gunungtanjung Kecamatan Gunungtanjung Kabupaten Tasikmalaya. Menurut Aziz dan Abdul (2003), studi kasus merupakan metode penelitian mengenai individu, lembaga, atau unit sosial tertentu dalam kurun waktu yang ditentukan serta berupa fenomena yang ada dan terjadi nyata dalam konteks kehidupan.

\section{Variabel Penelitian}

Variabel-variabel yang digunakan dalam penelitian ini, yaitu :

1. Produksi jagung (Y) adalah jumlah jagung yang dihasilkan dalam satu musim tanam dengan satuan pengukurannya adalah kilogram $(\mathrm{kg})$ 
2. Luas lahan $\left(\mathrm{X}_{1}\right)$ adalah luasan lahan yang digunakan untuk usahatani jagung dengan satuan pengukurannya adalah hektar (ha)

3. Benih jagung $\left(\mathrm{X}_{2}\right)$ adalah jumlah benih jagung yang digunakan petani untuk satu kali musim tanam dengan satuan pengukurannya adalah kilogram $(\mathrm{kg})$.

4. Pupuk Urea $\left(\mathrm{X}_{3}\right)$ adalah jumlah pupuk Urea yang digunakan petani untuk memupuk jagung selama satu kali musim tanam dengan satuan pengukurannya adalah kilogram $(\mathrm{kg})$.

5. Pupuk NPK $\left(X_{4}\right)$ adalah jumlah pupuk NPK yang digunakan petani untuk memupuk jagung selama satu kali musim tanam dengan satuan pengukurannya adalah kilogram $(\mathrm{kg})$.

6. Pupuk organik $\left(\mathrm{X}_{5}\right)$ adalah jumlah pupuk organik yang digunakan petani untuk memupuk jagung selama satu kali musim tanam dengan satuan pengukurannya adalah kilogram $(\mathrm{kg})$.

7. Pestisida $\left(\mathrm{X}_{6}\right)$ adalah jumlah pestisida yang digunakan petani selama satu kali musim tanam. Satuan pengukurannya adalah liter (lt).

8. Tenaga Kerja $\left(\mathrm{X}_{7}\right)$ adalah jumlah tenaga kerja total yang digunakan dalam usahatani jagung selama satu musim tanam. Pengukuran tenaga kerja dalam satuan HOK (Hari Orang Kerja) dengan mengabaikan apakah tenaga kerja berasal dari dalam keluarga maupun luar keluarga.

9. Efisiensi teknis (TE) adalah efisiensi teknis yang dicapai oleh petani pada usahatani jagung.

10. Inefisiensi teknis (ui) adalah inefisiensi teknis yang dicapai petani pada usahatani jagung

11. Umur petani $\left(Z_{1}\right)$ adalah umur petani saat musim tanam jagung yang dinyatakan dalam satuan tahun.

12. Pengalaman berusahatani $\left(Z_{2}\right)$ adalah lama pengalaman petani dalam menjalani usahatani yang dinyatakan dalam satuan tahun.

13. Pendidikan $\left(Z_{3}\right)$ adalah pendidikan yang telah ditempuh oleh petani dan dinyatakan dengan satuan tahun.

14. Tanggungan keluarga $\left(\mathrm{Z}_{4}\right)$ adalah banyaknya jumlah anggota keluarga yang menjadi tanggungan dari rumah tangga tesebut yang dinyatakan dalam satuan orang.

15. Penguasaan lahan $\left(Z_{5}\right)$ adalah luas lahan yang dikuasai yang digunakan untuk usahatani jagung dan dinyatakan dalam satuan hektar (ha)

16. Intensitas penyuluhan $\left(\mathrm{Z}_{6}\right)$ adalah berapa sering petani mendapatkan 
penyuluhan dalam satu tahun yang dinyatakan satuan kali.

\section{Tempat dan Waktu Penelitian}

Tempat penelitian dipilih secara purposive dengan pertimbangan bahwa menurut BPS Kabupaten tasikmalaya (2018) produktivitas jagung di Kecamatan Gunungtanjung masih rendah yaitu sebesar 5,75 ton/ha jagung pipilan kering dan Desa Gunungtanjung merupakan daerah yang mempunyai potensi lahan dalam pengembangan tanaman jagung di wilayah Kecamatan Gunungtanjung.

Arikunto (2012) menyatakan jika jumah populasinya kurang dari 100 orang, maka jumah sampelnya diambil secara keseluruhan, tetapi jika poplasinya lebih besar dari 100 orang, maka nisa diambi 10$15 \%$ atau $20-25 \%$ dari jumlah populasinya. Kelompoktani Sabilulungan diambil secara sengaja sebagai sampel kelompok dengan pertimbangan luas tanam jagung di kelompok tersebut paling luas. Selain itu, kelompok tersebut berushatani jagung secara kontinuitas. Anggota kelompoktani Sabilulungan sebanyak 77 orang, dan seluruhnya diambil sebagai sampel penelitian atau dilaksanakan dengan sensus.

\section{Metode Pengumpulan Data}

Data yang digunakan dalam penelitian ini adalah data primer dan sekunder. Data primer diambil melalui wawancara secara langsung dengan petani responden dengan menggunakan kuisioner sebagai alat pengumpul data pokok. Sedangkan data sekunder diperoleh dari dinas dan instansi yang terkait dengan kegiatan penelitian.

\section{Rancangan Analisis Data}

Analisis data dalam penelitian ini menggunakan persamaan fungsi CobbDouglas frontier stokhastik dengan metode OLS dan MLE. Secara matematis fungsi Cobb-Douglas frontier stokhastik dapat dituliskan sebagai berikut :

$$
\mathrm{Y}=\beta_{0} X_{1}^{\beta^{1}} X_{2} \beta^{2} X_{3}^{\beta^{3}} X_{4}^{\beta^{4}} X_{5} \beta^{5}+\varepsilon^{v i u i}
$$

Agar fungsi tersebut dapat ditaksir, maka persamaan tersebut perlu ditransformasikan ke dalam bentuk linear, yakni sebagai berikut:

$$
\begin{aligned}
\mathrm{LnY}=\operatorname{Ln} & \beta_{0}+\beta_{1} \operatorname{Ln} X_{1}+\beta_{2} \operatorname{Ln} X_{2}+\beta_{3} \operatorname{Ln} X_{3}+ \\
& \beta_{4} \operatorname{Ln} X_{4}+\beta_{5} \operatorname{Ln} X_{5+} \beta_{6} \operatorname{Ln} X_{6}+ \\
& \beta_{7} \operatorname{Ln} X_{7+}(\mathrm{vi}-\mathrm{ui})
\end{aligned}
$$

$\mathrm{Y} \quad:$ produksi jagung total $(\mathrm{kg})$

$\beta_{0} \quad:$ konstanta

$\beta_{1} \quad:$ koefisien parameter penduga

$X_{1} \quad: \quad(\mathrm{i}=1,2,3,4$ dan 5$)$

$X_{2} \quad:$ luas lahan (ha)

$X_{3} \quad:$ benih $(\mathrm{kg})$

$X_{4} \quad:$ pupuk Urea $(\mathrm{kg})$

$X_{5} \quad:$ pupuk NPK $(\mathrm{kg})$

$X_{6} \quad:$ pupuk organik $(\mathrm{kg})$

$X_{7} \quad:$ pestisida (lt)

(vi-ui) : tenaga kerja (HOK) one-side error term $(u i \leq 0)$ atau perubahan acak $\left(u_{i}\right.$ merepresentasikan 
inefisiensi teknis dari produksi).

Pendugaan efisiensi teknis petani kei adalah nilai harapan dari (-ui) yang dinyatakan dalam rasio berikut ini:

$$
\mathrm{TE}_{\mathrm{i}}=\frac{y_{i}}{\exp \left(x_{i} \beta\right)}=\frac{\exp \left(x_{i} \beta-u_{i}\right)}{\exp \left(x_{i} \beta\right)}=\exp \left(-u_{i}\right)
$$

$\mathrm{TE}_{\mathrm{i}}$ merupakan efisiensi teknis petani ke-i, yi adalah fungsi output deterministik (tanpa error term), dan ui yaitu peubah acak yang menggambarkan inefisiensi teknis dari usahatani ke-i yang diasumsikan bebas dan distribusinya terpotong normal dengan $\mathrm{N}(\mu \mathrm{i}, \sigma 2)$. Semua parameter yang terdapat dalam fungsi frontier stokhastik dengan efek inefisiensinya diperoleh dari program Frontier versi 4.1.

Dalam penelitian ini efek inefisiensi teknis dirumuskan sebagai berikut:

$$
\begin{aligned}
\mu \mathrm{i}= & \delta_{0}+\delta_{1} \mathrm{Z}_{1}+\delta_{2} \mathrm{Z}_{2}+\delta_{3} \mathrm{Z}_{3}+\delta_{4} \mathrm{Z}_{4}+ \\
& \delta_{5} \mathrm{Z}_{5}+\delta_{6} \mathrm{Z}_{6} \mathrm{~W}_{\mathrm{it}}
\end{aligned}
$$

Faktor yang diduga berpengaruh terhadap tingkat inefisiensi teknis petani jagung adalah:

$$
\begin{array}{ll}
\mu \mathrm{i} & : \text { inefisiensi teknis } \\
\delta_{0} & : \text { konstanta } \\
\delta_{1} & : \text { koefisien parameter penduga } \\
\mathrm{Z}_{1} & : \text { (i=1,2,3,4 dan 5) } \\
\mathrm{Z}_{2}: \text { umur petani (tahun) } \\
\mathrm{Z}_{3}: \text { pengalaman berusahatani (tahun) } \\
\mathrm{Z}_{4}: \text { tingkat pendidikan (tahun) } \\
\mathrm{Z}_{5}: \text { jumlah tanggungan keluarga }
\end{array}
$$

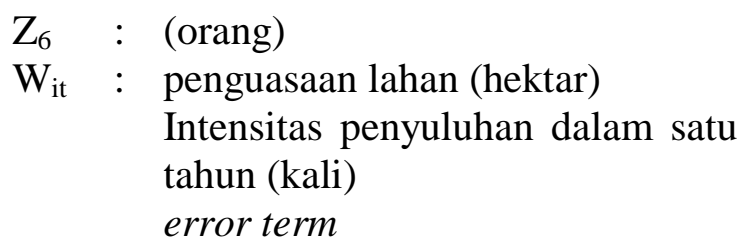

Efek inefisiensi fungsi frontier stokhastik diperoleh dari program Frontier 4.1 yang kemudian, efek inefisiensi dilakukan pengujian dengan metode statistik sehingga akan memberikan perkiraan nilai varians dari parameter dalam bentuk :

$$
\sigma_{\mathrm{s}}{ }^{2}=\sigma_{\mathrm{v}}{ }^{2}+\sigma_{\mathrm{u}}^{2} \text { dan } \gamma=\sigma_{\mathrm{u}}{ }^{2} / \sigma_{\mathrm{s}}^{2}
$$

Nilai $\gamma$ berada antara nol dan satu, dimana nilai kritis dapat menentukan penerimaan hipotesa yang dibuat.

\section{HASIL DAN PEMBAHASAN}

\section{Karakteristik Responden}

1. Umur

Produktivitas kerja seseorang dapat dipengaruhi oleh tingkat umur yang dimiliki.

Tabel 1. Sebaran Petani Responden Berdasarkan Usia Produktif

\begin{tabular}{ccrr}
\hline No & $\begin{array}{c}\text { Kelompok } \\
\text { Umur (Tahun) }\end{array}$ & $\begin{array}{c}\text { Jumlah } \\
\text { Petani }\end{array}$ & $\begin{array}{c}\text { Persentase } \\
(\mathbf{\%})\end{array}$ \\
\hline 1 & $<15$ & 0 & 0,00 \\
2 & $15-64$ & 53 & 68,83 \\
3 & $>64$ & 24 & 31,17 \\
\hline & Jumlah & $\mathbf{7 7}$ & $\mathbf{1 0 0 , 0 0}$ \\
\hline
\end{tabular}

Sumber: Hasil olah data primer, 2020

Secara keseluruhan petani sampel berada pada umur produktif (15-64 tahun). Menurut Sukmaningrum dan Imron (2017) 
penduduk usia produktif adalah penduduk yang masuk dalam rentang usia antara 1564 tahun. Penduduk usia itu dianggap sudah mampu menghasilkan barang maupun jasa dalam proses produksi.

\section{Tingkat Pendidikan}

Tingkat pendidikan dan pengetahuan petani berperan penting pada peningkatan pola usahatani.

Tabel 2. Sebaran Petani Responden Berdasarkan Tingkat Pendidikan Formal

\begin{tabular}{llrr}
\hline No & $\begin{array}{c}\text { Pendidikan } \\
\text { Formal }\end{array}$ & $\begin{array}{c}\text { Jumlah } \\
\text { Petani } \\
\text { (orang) }\end{array}$ & $\begin{array}{c}\text { Persentase } \\
\mathbf{( \% )}\end{array}$ \\
\hline 1 & Tidak Lulus SD & 1 & 1,30 \\
2 & Lulus SD & 46 & 61,04 \\
3 & Lulus SLTP & 19 & 23,38 \\
4 & Lulus SMA & 9 & 10,39 \\
5 & D3/S1 & 2 & 3,90 \\
\hline & Jumlah & $\mathbf{7 7}$ & $\mathbf{1 0 0 , 0 0}$ \\
\hline
\end{tabular}

Sumber: Hasil olah data primer, 2020

Pendidikan petani responden umunya lulusan Sekolah Dasar. Sehingga dapat dikatakan tingkat pendidikan sumberdaya manusia petani di lokasi penelitian masih tergolong rendah.

3. Pengalaman Usahatani

Pengalaman usahatani yang dimiliki petani dapat dijadikan sebagai pembelajaran untuk memperbaiki cara usahatani yang dilakukan.

Tabel 3. Sebaran

Petani Responden Berdasarkan Pengalaman Usahatani

\begin{tabular}{clrr}
\hline No & $\begin{array}{c}\text { Pengalaman } \\
\text { Usahatani (tahun) }\end{array}$ & $\begin{array}{c}\text { Jumlah } \\
\text { Petani }\end{array}$ & $\begin{array}{c}\text { Persentase } \\
(\boldsymbol{\%})\end{array}$ \\
\hline 1 & Rendah $(\leq 10)$ & 30 & 38,96 \\
2 & Sedang $(11-20)$ & 23 & 29,87 \\
3 & Tinggi $(\geq 21)$ & 24 & 31,17 \\
\hline & Jumlah & $\mathbf{7 7}$ & $\mathbf{1 0 0 , 0 0}$ \\
\hline
\end{tabular}

Sumber: Hasil olah data primer, 2020
Pengalaman usahatani petani responden dikategorikan rendah. Padmowihardjo (2002) menyatakan bahwa banyaknya pengalaman akan menetukan besarnya kemampuan belajar seseorang dalam melakukan proses menghubungkan (asosiasi) hal baru dengan hal yang telah dialami.

4. Tanggungan Keluarga

Tanggungan keluarga petani dapat berpengaruh terhadap produksi. Petani dengan jumlah tanggungan keluarga yang semakin banyak akan menuntut petani tersebut bekerja semakin keras dalam meningkatkan pendapatannya.

Tabel 4. Sebaran Petani Responden Berdasarkan Tanggungan Keluarga

\begin{tabular}{rlrr}
\hline No & $\begin{array}{c}\text { Pengalaman } \\
\text { Usahatani } \\
\text { (tahun) }\end{array}$ & $\begin{array}{c}\text { Jumlah } \\
\text { Petani }\end{array}$ & $\begin{array}{c}\text { Persentase } \\
(\boldsymbol{\%})\end{array}$ \\
\hline 1 & Sedikit $(\leq 3)$ & 50 & 64,94 \\
2 & Sedang $(4-5)$ & 22 & 28,57 \\
3 & Banyak $(\geq 6)$ & 5 & 6,49 \\
\hline & Jumlah & $\mathbf{7 7}$ & $\mathbf{1 0 0 , 0 0}$ \\
\hline
\end{tabular}

Sumber: Hasil olah data primer, 2020

Tanggungan keluarga petani responden umumnya berada pada kategori sedikit.

5. Luas Lahan

Lahan sebagai tempat tumbuh tanaman menjadi salah satu faktor penting dalam kegiatan usahatani. Luas lahan mempengaruhi terhadap jumlah 
penggunaan faktor input produksi dalam usahatani.

Tabel 5. Sebaran Petani Responden Berdasarkan Penguasaan Lahan

\begin{tabular}{clrr}
\hline No & $\begin{array}{c}\text { Pengalaman } \\
\text { Usahatani (tahun) }\end{array}$ & $\begin{array}{c}\text { Jumlah } \\
\text { Petani }\end{array}$ & $\begin{array}{c}\text { Persentase } \\
(\%)\end{array}$ \\
\hline 1 & Sempit $(<0.5)$ & 69 & 89,61 \\
2 & Menengah $(0.5-1)$ & 8 & 10,39 \\
3 & Luas $(>1)$ & 0 & 0,00 \\
\hline & Jumlah & $\mathbf{7 7}$ & $\mathbf{1 0 0 , 0 0}$ \\
\hline
\end{tabular}

Sumber: Hasil olah data primer, 2020

Hasil penelitian diketahui bahwa penguasaan lahan petani responden dominan sempit.

6. Intensitas Penyuluhan

$$
\text { Pendidikan nonformal yang }
$$

berhubungan dengan usahatani dapat berpengaruh pada keputusan serta kemampuan petani dalam penerapan inovasi teknologi baru untuk usahatani yang dilakukan.

Tabel 6. Sebaran Intensitas Penyuluhan Petani Responden dalam Setahun

\begin{tabular}{|c|c|c|c|}
\hline No & $\begin{array}{c}\text { Intensitas } \\
\text { penyuluhan } \\
\text { dalam setahun } \\
\text { (kali) }\end{array}$ & $\begin{array}{l}\text { Jumlah } \\
\text { Petani }\end{array}$ & $\begin{array}{c}\text { Persentase } \\
(\%)\end{array}$ \\
\hline 1 & Rendah $(1-4)$ & 19 & 24,68 \\
\hline 2 & Sedang $(5-8)$ & 51 & 66,23 \\
\hline \multirow[t]{2}{*}{3} & Tinggi $(9-12)$ & 7 & 9,09 \\
\hline & Jumlah & 77 & 100,00 \\
\hline
\end{tabular}

Sumber: Hasil olah data primer, 2020

Intensitas penyuluhan yang diterima petani responden dalam setahun berada pada kategori sedang.

\section{Analisis Fungsi Produksi Frontier}

\section{Stokhastik}

Analisis fungsi produksi Frontier Stokhastik pada penelitian ini menghitung nilai $\beta$ dan mencari nilai dugaan parameter sigma-squared $\left(\sigma^{2}\right)$. sebagai keragaman total yang disumbangkan oleh efek inefisiensi.

\begin{tabular}{|c|c|c|c|}
\hline Variabel & Kode & $\begin{array}{c}\text { Nilai } \\
\text { Koefisien }\end{array}$ & t-ratio \\
\hline Intersep & Beta 0 & 12,4838 & $30,7406^{*}$ \\
\hline $\begin{array}{l}\text { Luas lahan } \\
\left(\mathrm{X}_{1}\right)\end{array}$ & Beta 1 & 1,4979 & $11,0991^{*}$ \\
\hline $\operatorname{Benih}\left(\mathrm{X}_{2}\right)$ & Beta 2 & 0,0456 & 0,3246 \\
\hline $\begin{array}{l}\text { Pupuk Urea } \\
\left(\mathrm{X}_{3}\right)\end{array}$ & Beta 3 & $-0,9587$ & $-4,7660 *$ \\
\hline $\begin{array}{l}\text { Pupuk NPK } \\
\left(\mathrm{X}_{4}\right)\end{array}$ & Beta 4 & 0,1075 & 0,8225 \\
\hline $\begin{array}{l}\text { Pupuk } \\
\text { Organik }\left(\mathrm{X}_{5}\right)\end{array}$ & Beta 5 & $-0,1080$ & $-0,8671$ \\
\hline Pestisida $\left(\mathrm{X}_{6}\right)$ & Beta 6 & 0,0576 & 1,6266 \\
\hline $\begin{array}{l}\text { Tenaga } \\
\text { Kerja }\left(X_{7}\right)\end{array}$ & Beta 7 & 0,3664 & $6,9354 *$ \\
\hline $\begin{array}{l}\text { Sigma- } \\
\text { squared }\end{array}$ & $\sigma 2$ &, 0943 & \\
\hline Gamma & $r$ & 0,9999 & \\
\hline
\end{tabular}

Sumber: Data olahan primer, 2020

Keterangan: * nyata pada $\alpha=0,05$

Hasil analisis fungsi produksi Frontier diketahui bahwa nilai dugaan parameter $\sigma^{2}$ petani jagung sebesar 0,0943 dan nyata pada $\alpha 0,05$. Hal tersebut menunjukkan bahwa keragaman produksi jagung sebesar 9,43 persen. Nilai $\gamma$ sebesar 0,9999, artinya 99 persen variasi model disebabkan oleh pengaruh inefisiensi teknis pada proses produksi. Sedangkan 1 persen sisanya dikarenakan kesalahan stokhastik/noise.

Faktor yang berpengaruh terhadap efisiensi produksi yaitu luas lahan, pupuk urea, dan tenaga kerja. Hal ini dapat dilihat dari nilai t-hitung yang lebih besar dari 
nilai $\quad \mathrm{t}$-tabel $\mathrm{l}_{(63 ; 0,05)} \quad$ sebesar $\quad 1,9983$. Sedangan variabel benih, pupuk NPK, pupuk organik, dan pestisida tidak berpengaruh nyata terhadap efisiensi produksi. Hal ini dapat dilihat dari nilai thitung yang lebih kecil dari nilai t$\operatorname{tabel}_{(63 ; 0,05)}$ sebesar 1,9983.

Luas lahan berpengaruh nyata dan berkorelasi positif, artinya bahwa dengan peningkatan penggunaan luas lahan maka akan meningkatkan produksi jagung. Darmayanti, dkk (2019) menyatakan bahwa luas lahan berpengaruh nyata terhadap produksi jagung pada lahan kering dan sawah. Lahan berpengaruh positif karena dengan penggunaan lahan yang semakin luas, maka jumlah populasi tanaman dapat bertambah, sehingga diharapkan dapat meningkatkan jumlah produksi.

Benih berkorelasi positif tapi tidak signifikan. Hal ini karena benih yang digunakan oleh petani umumnya berasal dari jagung lokal hasil panen sendiri.

Pupuk Urea berpengaruh nyata dan berkorelasi negatif. Hal tersebut berarti bahwa dengan peningkatan penggunaan pupuk Urea pada tanaman jagung justru dapat menurunkan produksi jagung yang dihasilkan. Hal ini menunjukkan bahwa penggunaan pupuk urea pada usahatani jagung sudah berlebih. Keadaan ini mengindikasikan lahan jagung yang berada pada kondisi subur. Selain itu, pada usahatani jagung yang dilakukan digunakan pupuk organik berupa limbah ternak ayam broiler.

Pupuk NPK berkorelasi positif tapi tidak signifikan. Hal ini karena pupuk NPK yang digunakan oleh petani di tempat penelitian masih rendah, karena petani responden cenderung lebih memilih untuk memperbanyak penggunaan pupuk yang mengandung unsur $\mathrm{N}$.

Pupuk organik berkorelasi negatif dan tidak signifikan. Hal ini karena jenis pupuk organik yang digunakan berupa limbah ternak unggas. Nilai koefisien bertanda negatif menunjukkan adanya indikasi bahwa penggunaan pupuk organik oleh petani responden telah melewati batas maksimum.

Pestisida berkorelasi positif tapi tidak signifikan. Hal ini karena intensitas serangan OPT pada tanaman jagung petani responden masih berada di bawah ambang batas ekonomis. Hasil penelitian ini sesuai dengan penelitian Widi dan Isyanto (2020).

Tenaga kerja berpengaruh nyata dan berkorelasi positif. Artinya bahwa dengan peningkatan penggunaan tenaga kerja, akan meningkatkan produksi jagung. Purwanto, dkk (2015) menyatakan bahwa tenaga kerja berpengaruh nyata terhadap produksi jagung hibrida. Penambahan 
tenaga kerja dalam usahatani jagung berupa adanya aktivitas pemeliharaan seperti penyiangan gulma, pembumbunan dan ketepatan dalam waktu pemupukan.

Penjumlahan nilai koefisien regresi yang sekaligus menunjukkan nilai elastisitas produksi menunjukkan bahwa usahatani jagung di Desa Gunungtanjung Kecamatan Gunungtanjung Kabupaten Tasikmalaya berada pada kenaikan skala usaha yang konstan (constan return to scale).

\section{Efisiensi Teknis}

Efisiensi teknis merupakan gambaran dari pengelolaan input faktor produksi yang digunakan oleh petani. Kisaran nilai efisiensi teknis berada pada 0 sampai 1 . Kurniawan (2008) menyatakan bahwa usahatani dikatakan efisien secara teknis jika nilai ET >0,8.

Tabel 8. Efisiensi Teknis pada Usahatani Jagung di Desa Gununngtanjung Kecamatan Gunungtanjung

\begin{tabular}{lrr}
\hline $\begin{array}{l}\text { Interval efisiensi } \\
\text { teknis }\end{array}$ & $\begin{array}{l}\text { Jumlah } \\
\text { (orang) }\end{array}$ & \multicolumn{2}{c}{$\%$} \\
\hline $0,41-0,50$ & 4 & 5,19 \\
$0,51-0,60$ & 12 & 15,58 \\
$0,61-0,70$ & - & - \\
$0,71-0,80$ & 6 & 7,79 \\
$0,81-0,90$ & 21 & 27,27 \\
$0,91-1,00$ & 34 & 44,16 \\
\hline Jumlah & $\mathbf{7 7}$ & $\mathbf{1 0 0 , 0 0}$ \\
\hline Rata-rata & & $\mathbf{0 , 8 3}$ \\
\hline Minimum & & $\mathbf{0 , 4 6}$ \\
\hline Maksimum & & $\mathbf{1 , 0 0}$ \\
\hline Sumber: Datan
\end{tabular}

Sumber: Data olahan primer, 2020
Nilai rata-rata efisiensi teknis pada petani jagung sebesar 0,83, artinya usahatani jagung yang dilakukan petani dapat dikatakan sudah efisien.

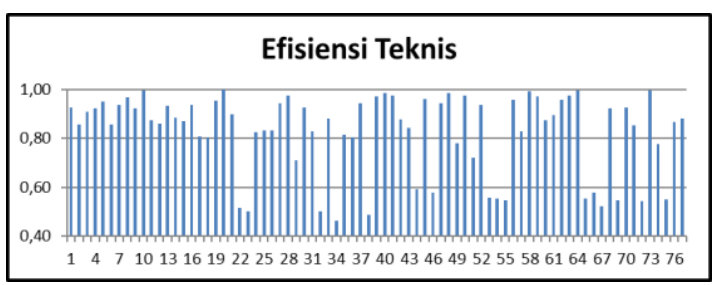

Gambar 1. Efisiensi Teknis Usahatani Jagung di Desa Gunungtanjung Kecamatan Gunungtanjung Kabupaten Tasikmalaya

Secara visual dapat dilihat bahwa kegiatan penyuluhan dan bimbingan teknis yang dilaksanakan oleh penyuluh sebaiknya difokuskan pada petani yang mencapai efisiensi teknis di bawah 0,80 sehingga lebih tepat sasaran.

\section{Inefisiensi Teknis}

Efek inefisiensi teknis yang dianalisis lebih menggambarkan karakteristik individu petani. Efek inefisiensi ini menjelaskan pengaruh karakteristik individu petani terhadap tingkat efisiensi teknis yang dapat dicapai petani responden

Tabel 9. Pendugaan Parameter MaximumLikelihood Model Inefisiensi Teknis Usahatani Jagung

\begin{tabular}{lcrr}
\hline \multicolumn{1}{c}{ Variabel } & Kode & $\begin{array}{c}\text { Nilai } \\
\text { Koefisien }\end{array}$ & t-ratio \\
\hline Intersep & Delta 0 & $-0,4756$ & $-0,4963$ \\
Umur $\left(Z_{1}\right)$ & Delta 1 & $-0,0225$ & $-0,0973$ \\
Pendidikan & Delta 2 & $-0,2475$ & $-1,2167$ \\
$\left(Z_{2}\right)$ & & & \\
$\begin{array}{l}\text { Pengalaman } \\
\text { berusahatani }\end{array}$ & Delta 3 & $-0,1316$ & $-1,5165$ \\
& & &
\end{tabular}


$\left(\mathrm{Z}_{3}\right)$

\begin{tabular}{lccc}
$\begin{array}{l}\text { Tanggungan } \\
\text { keluarga } \\
\left(\mathrm{Z}_{4}\right)\end{array}$ & Delta 4 & $-0,1569$ & $-1,4699$ \\
$\begin{array}{l}\text { Penguasaan } \\
\text { lahan }\left(\mathrm{Z}_{5}\right)\end{array}$ & Delta 5 & $-0,3702$ & $-4,5832^{*}$ \\
$\begin{array}{l}\text { Intensitas } \\
\begin{array}{l}\text { Penyuluhan } \\
\left(\mathrm{Z}_{6}\right)\end{array}\end{array}$ & Delta 6 & 0,3379 & $2,0367^{*}$ \\
\hline
\end{tabular}

Sumber: Olah data primer, 2020

Keterangan: *nyata pada $\alpha=0,05$

Hasil analisis efek inefisiensi teknis diketahui bahwa umur petani tidak berpengaruh nyata terhadap inefsiesi teknis usahatani jagung. Nilai koefisiensi bertanda negatif menunjukkan bahwa peningkatan umur petani akan meningkatkan efisiensi teknis.

Tingkat pendidikan tidak berpengaruh nyata terhadap inefisiensi teknis usahatani jagung. Nilai koefisiensi bertanda negatif menunjukkan bahwa semakin tinggi tingkat pendidikan yang ditempuh oleh petani, maka semakin meningkat efisiensi teknis yang dicapai oleh petani dalam melaksanakan usahatani jagung.

Pengalaman berusahatani tidak berpengaruh nyata terhadap inefisiensi teknis usahatani jagung. Nilai koefisiensi bertanda negatif menunjukkan bahwa semakin bertambah pengalaman petani, maka semakin meningkat efisiensi teknis yang dicapai oleh petani dalam melaksanakan usahatani jagung. Semakin bertambahnya pengalaman petani dalam melaksanakan usahatani jagung, maka semakin meningkat keterampilan teknis petani yang mengakibatkan peningkatan efisiensi teknis. Hasil penelitian ini sesuai dengan penelitian Isyanto dan Maemunah (2017).

Jumlah tanggungan keluarga tidak berpengaruh nyata terhadap inefisiensi teknis usahatani jagung. Nilai koefisiensi bertanda negatif menunjukkan bahwa semakin bertambah jumlah tanggungan keluarga, maka semakin meningkat efisiensi teknis yang dicapai oleh petani dalam melaksanakan usahatani jagung

Penguasaan lahan berpengaruh nyata dan berkorelasi negatif. Hal tersebut berarti bahwa peningkatan luas penguasaan lahan petani dapat meningkatkan efisiensi usahatani jagung. Hidayah, dkk (2013) menyatakan bahwa luas lahan berpengaruh nyata terhadap efisiensi teknis.

Intensitas penyuluhan berpengaruh nyata terhadap inefisiensi teknis usahatani jagung. Nilai koefisiensi bertanda positif menunjukkan bahwa peningkatan intensitas penyuluhan akan menurunkan tingkat efisiensi teknis yang dicapai oleh petani. Hal ini dikarenakan penyuluhan yang diterima tidak selalu terfokus pada teknis budidaya jagung, melainkan pada berbagai komoditas pertanian, sehingga tidak berpengaruh terhadap efisiensi teknis 
usahatani jagung. Menurut Malta (2016), interaksi petani dengan penyuluh dapat meningkatkan kemandirian petani dalam pengambilan keputusan untuk keberlanjutan usahatani dengan lebih intensifnya interaksi penyuluh dengan petani melalui kegiatan-kegiatan penyuluhan yang sesuai dengan kebutuhan dan masalah petani.

\section{KESIMPULAN DAN SARAN}

\section{Kesimpulan}

Berdasarkan hasil penelitian dapat disimpulkan bahwa produksi jagung secara nyata dipengaruhi oleh luas lahan, pupuk urea, dan tenaga kerja. Luas lahan dan tenaga kerja berkorelasi positif, sedangkan pupuk urea berkorelasi negatif terhadap produksi jagung. Tingkat efisiensi teknis usahatani jagung yang dicapai oleh petani dan rata-rata 0,83 . Sedangkan untuk faktor yang mempengaruhi inefisiensi teknis usahatani jagung secara nyata adalah penguasan lahan dan intensitas penyuluhan.

\section{Saran}

Saran yang dapat diberikan yaitu, penambahan areal tanam jagung dapat dilakukan pada lahan sawah sebagai pergiliran tanam untuk padi sawah. Dalam penggunaan pupuk urea hendaknya sesuai dengan ketentuan pemupukan berimbang.
Sementara untuk penyuluhan yang diberikan hendaknya sesuai dengan kebutuhan petani dengan memperhatikan jenis komoditas yang petani usahakan, dan difokuskan pada petani yang belum mencapai efisiensi teknis.

\section{DAFTAR PUSTAKA}

Arikunto, S. 2012. Prosedur Penelitian. Jakarta: Rineka Cipta.

Aziz. S.R. \& Abdul. 2003. Memahami Fenomena Sosial Melalui Studi Kasus. Jakarta: PT Raja Grafindo Persada.

Badan Pusat Statistik. 2018. Kabupaten Tasikmalaya dalam Angka 2018. Tasikmalaya: Badan Pusat Statistik.

Darmawan, D. 2014. Metode Penelitian Kuantitatif. Bandung: PT Remaja Rosdakarya.

Darmayanti, N.W.S., Winandi, R., dan Tinaprilla, N. 2019. Analisis Dayasaing Jagung di Wilayah Sentra Produksi di Indonesia Dengan Pendekatan Policy Analysis Matrix (PAM). Forum Agribisnis, 8(2), 137154.

Hidayah, I., Waas, E.D. dan Susanto, A.N. Analisis Efisiensi Teknis Usahatani Padi Sawah Irigasi di Kabupaten Seram Bagian Barat. Jurnal Pengkajian dan Pengembangan Teknologi Pertanian, 16(2): 122-131. Isyanto, A.Y. dan Maemunah, S. 2017. Faktor Penentu Inefisiensi Teknis Pada Usaha Ternak Kambing Peranakan Ettawa (Studi Kasus di Kelompok Agribisnis As-Salam Kota Tasikmalaya). Mimbar Agribisnis: Jurnal Pemikiran Masyarakat Ilmiah Berwawasan Agribisnis, 3(2): 169184.

Kurniawan, A. Y. 2008. Analsis Efisiensi Ekonomi dan Daya Saing Usahatani 
Jagung Pada Lahan Kering di Kabupaten Tanah Laut Kalimantan Selatan [Tesis]. Bogor: Insitut Pertanian Bogor.

Kusumawardani, 2001. Teori Produksi dan Aplikasi Manufaktur. Jakarta: Grafindo.

Malta. 2016. Faktor-Faktor yang Berhubungan dengan Kemandirian Petani dalam Pengambilan Keputusan untuk Keberlanjutan Usahatani (Kasus: Petani di Desa Sukaharja - Kabupaten Bogor). Sosiohumaniora, 18(2): 118 - 124.

Purwanto, A.Z.A., Hadayani dan Muis, A. 2015. Analisis Produksi dan Pendapatan Usahatani Jagung Hibrida di Desa Modo Kecamatan Bukal Kabupaten Buol. Jurnal Agroland, 22(3): 205-215.

Pusat Data dan Sistem Informasi Pertanian. 2019. Buletin Konsumsi Pangan. Jakarta: Kementrian Pertanian.

Suarni. 2009. Pemanfaatan Jagung Masak Susu sebagai Produk Olahan Mendukung Pemenuhan Pangan Menunjang Hidup Sehat. Prosiding Seminar Nasional BBP2TP. Palu. p. 175-182.

Sukmaningrum, A. dan Imron, A. 2017. Memanfaatkan Usia Produktif dengan Usaha Kreatif Industri Pembuatan Kaos Pada Remaja di Gresik. Paradigma, 5(3): 1-6.

Tangendjaja B., Yusdja, Y., dan Ilham, N. 2002. Analisis Ekonomi Permintaan
Jagung untuk Pakan. Badan Penelitian dan Pengembangan Sosial Ekonomi Pertanian, Bogor. Badan Litbang-Departemen Pertanian.

Mandei, J.R. 2015. Efisiensi Teknis Usahatani Jagung di Kecamatan Remboken Kabupaten Minahasa. ASE, 11(1): 28 - 37.

Manurung, H.A., Asmara, R., dan Maarthen, N. 2018. Analisis Efisiensi Teknis Usahatani Jagung di Desa Maindu Kecamatan Montong, Kabupaten Tuban: Menggunakan Pendekatan Stochastik Frontier Analysis (SFA). Jurnal Ekonomi Pertanian dan Agribisnis, 2(4): 293 302.

Sumarno, J., Harianto., dan Kusnadi, N. 2015. Peningkatan Produksi dan Efisiensi Usahatani Jagung melalui Penerapan Pengelolaan Tanaman Terpadu (PTT) di Gorontalo. Jurnal Management dan Agriisnis, 12(2): 79-91.

Utama, S.P. 2004. Efisiensi Teknis Usahatatani Jagung di Desa Suka Pindah. AGRISEP, 2(2): 126-134.

Widi, R.H. and Isyanto, A.Y. 2020. Determinants of Technical Inefficiencies of Sweet Potato Farming in Kuningan District. Proceedings of The International Conference on Agriculture, Social Sciences, Education, Technology and Health (ICASSETH 2019). pp. 118120. 